\title{
Rising Food Insecurity and Conservative Policy in the US:
}

\section{Impact on the Elderly}

\author{
Peter S. Arno ${ }^{1,2^{*}}$, Kenneth A. Knapp ${ }^{3}$, Stephan Russo ${ }^{4} \&$ Deborah Viola ${ }^{3,5}$ \\ ${ }^{1}$ Political Economy Research Institute, University of Massachusetts, Amherst, Massachusetts, USA \\ ${ }^{2}$ City University of New York Institute for Health Equity, Lehman College, Bronx, NY, USA \\ ${ }^{3}$ Center for Long Term Care Research \& Policy, New York Medical College, Valhalla, NY, USA \\ ${ }^{4}$ Goddard Riverside Community Center, New York, NY, USA \\ ${ }^{5}$ Center for Regional Healthcare Innovation, Westchester Medical Center, Valhalla, NY, USA \\ * Peter S. Arno, E-mail: parno22@gmail.com
}

\begin{abstract}
Food insecurity, a critical problem in the developing world, has recently received increased attention among wealthy nations. Food insecurity, broadly defined, is when a lack of resources prevents household members from having enough food. In the US, food insecurity has been rising while social safety net programs to ameliorate hunger among at-risk households have been targeted for cuts by conservatives. Our main objective was to assess the prevalence and impact of food insecurity among the elderly. In a survey of 500 older, homebound meal clients in New York City, we found that nearly one in five (17\%) is food insecure, $89 \%$ endure chronic health problems, $14 \%$ live with severe functional impairments, 38\% are in declining health, and 10\% experience unmet needs for services. New York City's oldest community residents have serious health problems, multiple unmet social service needs, and often suffer from food insecurity. Understanding the relationship between these issues is critical if community organizations and government agencies at all levels - even in wealthy countries-are to be more effective in assuring the well being of their oldest residents.
\end{abstract}

\section{Keywords}

food insecurity, elderly, social safety net, health status, unmet needs

\section{Introduction}

Food insecurity is a critical problem in the developing world and has recently received increased attention among developed countries including the United States. The International Fund for Agricultural Development (IFAD), the Food and Agriculture Organizations (FAO), and the World Food Programme (WFP) all are internationally led agencies affiliated with the United Nations whose missions are focused on eradicating hunger in the world's poorest countries. While their efforts have contributed to reducing world hunger in recent years, 805 million people are still chronically undernourished (FAO, IFAD, \& WFP, 2014), and food insecurity is expected to rise in the developing 
world in the coming decade (Rosen, Meade, Fuglie, \& Rada, 2014). In wealthy countries, food insecurity is an issue faced by many vulnerable groups including the poor and disabled who range from young children to the very old. Since the early 2000 s, the prevalence of food insecurity has been rising in the US (Hoefer \& Curry, 2012). The correlation between recent trends and increased poverty, unemployment, and widening wage disparities (Andrews \& Smallwood, 2012), underscores the need to integrate the nation's health, economic, and social policies.

The United States Department of Agriculture defines "food insecure" households as those that have "had difficulty at some time during the year providing enough food for all their members due to a lack of resources." (Coleman-Jensen, Nord, \& Singh, 2013). This definition is not inconsistent with the definition adopted by the FAO, which includes four dimensions: availability, access, stability, and utilization (FAO, IFAD, \& WFP, 2014). Approximately 15\% of US households (17.6 million households including 49 million persons) were food insecure in 2012. Perhaps more disturbing, nearly $6 \%$ had very low food security, which means that the level of food intake "for one or more household members was reduced and their eating patterns were disrupted at times during the year because the household lacked money and other resources for food." (Coleman-Jensen, Nord, \& Singh, 2013)

In the US, most public attention to the issue of food insecurity has focused on the family, particularly the impact on children, and programs have been developed nationally and locally to address the transient nature of this problem (U.S. Department of Agriculture, 2013; Nord, 2013). The elderly population is an under-studied group with regard to food insecurity. This may be a result of tradition (the elderly were primarily cared for by family or institutions) or of the perception that income support programs, such as Social Security, assure that the elderly are food secure (Ziliak \& Gundersen, 2011).

However, the dynamics of food insecurity in the US have changed considerably in the past decade. The increased demand for meal programs by seniors indicates that food insecurity among the elderly continues to rise. The 2014 study Hunger in America reveals that a disproportionate number of individuals visiting food pantries are the elderly and that more than half of these individuals return monthly (Weinfield, Mills, Borger, Gearing, Macaluso, Montaquila, \& Zedlewski, 2014). The US Government Accountability Office (GAO, 2011) found that following the economic downturn that began in late 2007 , nearly $80 \%$ of senior-serving agencies reported an increased demand for nutrition assistance and $20 \%$ reported that they were unable to meet the increased demand. Moreover, $90 \%$ of low-income seniors who could not afford proper nutrition had no access to federal meal programs.

We posit that the situation of the elderly is unique, particularly for our oldest residents. First, food insecurity is not a temporary problem for the elderly, the majority of whom live alone and rely increasingly upon a wide range of home and community-based services. In addition, they suffer disproportionately from chronic illnesses, functional impairments, and dementia. Any of these factors can put an older person at a higher risk of food insecurity, which in turn may exacerbate underlying medical conditions (Ziliak \& Gundersen, 2014; Seligman, Bolger, Guzman, \& Bibbins-Domingo, 2014). 
The aging of the US population - a phenomenon shared by other developed countries - lends further urgency to the issue of food insecurity among older people. People aged 85 and over represent the nation's fastest growing segment of the population (He, Sengupta, Velkoff, \& DeBarros, 2005). About $14 \%$ of the American population, more than 43 million people, are over the age of 65 - and that number is expected to double by 2050 .

A powerful wave of conservative ideology, both within and outside the government, in conjunction with the recent financial crisis has resulted in continual challenges to America's safety net programs, including those that keep the elderly out of poverty. For example, nearly all of the proposals to address the modest long-term fiscal imbalance projected for Social Security would result in a cut in benefits. Social Security, a national insurance program primarily intended to provide retirement and disability benefits, keeps more than a third of seniors from falling into poverty (Van de Water, Sherman, \& Ruffing, 2013). In addition, the US Congress allowed a temporary increase to the Supplemental Nutrition Assistance Program (SNAP, formerly known as Food Stamps) to lapse at the end of 2013, and under Agricultural Act of 2014 (the Farm Bill), \$8.6 billion dollars of additional cuts to the SNAP program were imposed over a 10-year period (Bolen, Rosenbaum, \& Dean, 2014). The SNAP program, which offers nutrition assistance to tens of millions of low-income families and individuals including the elderly, is the largest and most effective element of the domestic hunger safety net.

These attacks on aid to the poor and to older people follow a recent period of economic stagnation in the US that has had a devastating impact on older segments of the population. Along with increased unemployment (with the average duration of unemployment at its highest level since record-keeping began in 1948) (Greenstone \& Looney, 2011), the values of financial investments and homes owned by older Americans dropped significantly. A recent survey by AARP found that between 2007 and 2010, a quarter of Americans aged 50 and over said they had exhausted or used up all of their savings, $12 \%$ had lost their health insurance, $3.6 \%$ had filed for bankruptcy, and $2.8 \%$ had either lost their homes to foreclosure or been forced to sell them (Rix, 2011). Those aged 55 to 64 saw their median family net worth decline by nearly a third (U.S. Congress Joint Economic Committee Chairman's Staff, 2012), leaving three quarters of all Americans in this age group with less than $\$ 30,000$ in their retirement accounts (Schwartz Center for Economic Policy Analysis, 2013). Without a clearer understanding of the nature of food insecurity among the elderly, including its relationship to health and unmet needs and the impact of conservative social policy, our society may be guilty of sabotaging the future of all but its most affluent members.

To shed light on the impact of threatened and real cuts to SNAP and other safety net programs on food insecurity in the US, especially in regards to the older population, we engaged in a study of homebound seniors in New York City. In light of the current political environment and emphasis on weakening the social safety net, this clearly has significant public policy implications. 


\section{Design and Methods of Analysis}

In partnership with Goddard Riverside Community Center, a longstanding, multi-service community-based organization in New York City, we designed a survey that its social workers could use to collect information about their clients' levels of food security, overall health status, chronic health conditions, functional impairment, level of independence, and unmet social service needs. Those interviewed were drawn from a population of elderly, homebound residents of the Upper West Side of Manhattan in New York City. Clients were either receiving home delivered meals or applying for this service at the time they were interviewed. The social workers conducted the interviews in person, read each question aloud, and recorded all replies. Interviews took approximately 30 minutes to complete. The social workers made additional open-ended notes based on their inspection or visual impressions of the home environment. A total of 500 interviews were conducted over a period of 12 months. To improve statistical analyses by race/ethnicity, we oversampled for Hispanics and non-Hispanic Blacks. Food security questions were adopted from the scale recommended by the United States Department of Agriculture, which includes relevant items from the Current Population Survey's Food Security Supplement (Bickel, Nord, Price, Hamilton, \& Cook, 2000). Questions that serve as the basis of the food security scale may be categorized as describing three situations: (1) anxiety or perception that the household food budget or food supply was inadequate; (2) perceptions that the food eaten was inadequate in quality; or (3) instances or consequences of reduced food intake. Based upon ten survey questions, food security status was measured on a scale from zero to ten and the results were divided into four categories: very low, low, marginal, and high food security. For purposes of this study, clients were considered food insecure if they did not score in the "high food security" range.

Survey respondents' functional status was assessed using two widely used measures - the Katz Activities of Daily Living (ADL) Index and the Lawton Instrumental Activities of Daily Living (IADL). The Katz ADL Index is a measure of functionality based upon ability to perform activities of daily living without assistance (Katz, Downs, Cash, \& Grotz, 1970). The Lawton Instrumental Activities of Daily Living Scale is widely used to assess independent living skills that are considered more complex than basic ADLs (Lawton \& Brody, 1969). IADLs are not necessary for fundamental functioning, but permit an individual to live independently in a community. Since IADL function is often lost before ADL function, assessment of IADLs may identify incipient cognitive or physical decline in an otherwise capable and healthy older adult (Ward, Jagger, \& Harper, 1998). A combined summary score ranges from 0 to 8 (low function to high function) on the Lawton Scale.

We examined differences in food security by health status, race and ethnicity, gender, whether or not people were living alone, and whether or not they were receiving home-delivered meals. We also examined linkages between food insecurity and unmet needs for social services and between health status/functional impairment and race/ethnicity. Survey data were analyzed using Fisher's exact test. 


\section{Results}

\subsection{Socio-Demographic Profile of Respondents}

The majority of clients were female (59\%) and lived alone (65\%). (Table 1) Nearly nine in ten (86\%) reported annual household incomes below $\$ 25,000$ (US \$). Of those interviewed, $44 \%$ were non-Hispanic whites, $25 \%$ were non-Hispanic Blacks, and $28 \%$ were Hispanic. The average client was 80 years old.

Table 1. Demographics \& Living Arrangements

\begin{tabular}{lll}
\hline & Percent & Number of observations \\
\hline Race/Ethnicity & & \\
White, non-Hispanic & $44 \%$ & 493 \\
Black, non-Hispanic & $25 \%$ & 493 \\
Other race, non-Hispanic & $3 \%$ & 493 \\
Hispanic & $28 \%$ & 493 \\
Living alone & $65 \%$ & 500 \\
Female & $59 \%$ & 499 \\
Household Income $<\$ 25,000$ & $86 \%$ & 493 \\
\hline
\end{tabular}

\subsection{Food Insecurity and Home-Delivered Meals}

Nearly one fifth $(17 \%)$ of clients interviewed lived in food insecure households, defined for our purposes as those whose survey responses indicated very low $(3 \%)$, low $(7 \%)$ or marginal (7\%) food security (Table 2). Whites (including both Hispanic and non-Hispanic whites) were somewhat less likely to live in food insecure households than non-whites (14\% vs. $20 \% ; P=.038)$. Seniors living in highly food secure households were more likely than those in food insecure households to experience good, very good, or excellent health ( $49 \%$ vs. $38 \% ; P=.041)$.

Table 2. Food Secure Vs. Food Insecure Households, by Health Status and Demographics

\begin{tabular}{llll}
\hline & Food secure & Food insecure & $P$ \\
\hline Total sample & $83 \%$ & $17 \%$ & \\
& $(\mathrm{n}=412)$ & $(\mathrm{n}=82)$ & \\
& & & \\
Health status & $(\mathrm{n}=405)$ & $(\mathrm{n}=81)$ & \\
Excellent, very good, or good & $48 \%$ & $37 \%$ & 0.043 \\
Fair or poor & $52 \%$ & $63 \%$ & \\
\hline
\end{tabular}




\begin{tabular}{llll}
\hline Race & $(\mathrm{n}=412)$ & $(\mathrm{n}=81)$ & \\
Whites* & $86 \%$ & $14 \%$ & \\
Non-whites & $80 \%$ & $20 \%$ & 0.038 \\
& & & \\
Gender & $(\mathrm{n}=412)$ & $(\mathrm{n}=82)$ & \\
Female & $84 \%$ & $16 \%$ & 0.327 \\
Male & $82 \%$ & $18 \%$ & \\
& & & \\
Lives Alone & $(\mathrm{n}=411)$ & $(\mathrm{n}=82)$ & \\
Yes, lives alone & $82 \%$ & $18 \%$ & 0.089 \\
Does not live alone & $87 \%$ & $13 \%$ & \\
& & & \\
Receiving home-delivered meals when interviewed & $(\mathrm{n}=406)$ & $(\mathrm{n}=78)$ & \\
Yes, receiving meals & $87 \%$ & $13 \%$ & \\
Not receiving meals & $50 \%$ & $50 \%$ & \\
\hline
\end{tabular}

* Whites include both Hispanic and non-Hispanic whites.

$P$-value based on Fisher's exact test.

Of the 500 people interviewed, $46(9 \%)$ were being assessed for eligibility for home-delivered meals (HDMLs) based upon referrals and were not receiving meals at the time of their interview. Not surprisingly, those receiving home-delivered meals were considerably more likely than those not receiving meals to be living in food secure households ( $87 \%$ vs. $50 \% ; P<.001)$.

Meal recipients also reported better health status than non-HDML respondents. About half $(49 \%)$ of HDML clients reported good, very good, or excellent health, in contrast with only $19 \%$ of non-HDML respondents $(P=.002)$. Individuals receiving meals were also less likely to report that their health had deteriorated over the past year, with $36 \%$ of HDML clients saying that they were in "somewhat worse" or "much worse" health than a year ago compared with $68 \%$ of non-HDML respondents $(P<.001)$. Among HDML clients, one in five reported to be in "somewhat better" or in "much better" health compared with one year ago - an improvement in health that was reported by just $3 \%$ of those not receiving home-delivered meals $(P<.001)$.

\subsection{Overall Health Status, Race/Ethnicity and Age}

The homebound seniors in our sample suffer from a variety of health problems. More than one-half (54\%) answered "fair" or "poor" when asked to rate their health status (Table 3). This compares unfavorably with seniors nationally, where "only" $26 \%$ of those aged 75 and older are in fair or poor health (Schiller, Lucas, Ward, \& Peregoy, 2014). A substantial percentage (38\%) of the homebound seniors we analyzed reported deteriorating health, stating that their health was worse compared with one year earlier. 
Table 3. Self-Reported Health Status

\begin{tabular}{llll}
\hline $\begin{array}{l}\text { In general, would you } \\
\text { say your health is: }\end{array}$ & $(\mathrm{n}=490)$ & $\begin{array}{l}\text { Compared to one year ago, how would } \\
\text { you rate your health in general now? }\end{array}$ & $(\mathrm{n}=457)$ \\
\hline Excellent & $4 \%$ & Much better & $4 \%$ \\
Very Good & $6 \%$ & Somewhat better & $16 \%$ \\
Good & $37 \%$ & About the same & $43 \%$ \\
Fair & $40 \%$ & Somewhat worse & $27 \%$ \\
Poor & $14 \%$ & Much worse & $11 \%$ \\
\hline
\end{tabular}

Percentages may not sum to $100 \%$ due to rounding.

In general, non-Hispanic Whites reported better health than both non-Hispanic Blacks and Hispanics, but the disparity between Hispanics and non-Hispanics is even wider. Thirteen percent of Whites are in "very good" or "excellent" health, about twice the rate reported by either Blacks (7\%) or Hispanics (5\%). However, similar percentages of non-Hispanic Whites and Blacks (40\% and 39\%, respectively) reported "good" health, both of which are higher than for Hispanics (28\%). Two-thirds of Hispanics reported "fair" to "poor" health, which is considerably higher than for non-Hispanic Whites and Blacks (47\% and 53\%). These differences are statistically significant $(P=.045)$.

\subsection{Chronic Health Conditions, Functional Impairment and Independence}

A substantial proportion (89\%) of clients endure one or more of six chronic health conditions: arthritis, asthma, cancer, diabetes, heart disease, and high blood pressure (prevalence of each is shown in Table 4). Two or more of these chronic illnesses were reported by $59 \%$ of non-Hispanic whites, lower than the $69 \%$ of non-Hispanic Blacks and $72 \%$ of Hispanics $(P=.058)$. Nearly two-thirds of clients $(64 \%)$ reported some other health problem besides the six listed in Table 4.

Table 4. Prevalence of Six Chronic Health Conditions

\begin{tabular}{ll}
\hline Have you ever been told by a doctor or health professional that you have: & Percent replying "Yes" \\
\hline Arthritis & $55 \%$ \\
Asthma & $14 \%$ \\
Cancer & $17 \%$ \\
Diabetes & $30 \%$ \\
Heart disease & $37 \%$ \\
High blood pressure & $60 \%$ \\
\hline
\end{tabular}

Many clients were unable to perform one or more of six basic self-care tasks or "activities of daily living" (ADLs): bathing (34\%), dressing (20\%), toileting (18\%), moving in and out of bed/chair (30\%), bowel and bladder control (28\%), and feeding self (7\%). Based on the Katz scale, $14 \%$ of our survey's 
homebound seniors live with a severe impairment (ability to perform $\leq 2$ of the activities listed), and another $19 \%$ have a moderate impairment (ability to perform 3-4 of the activities listed). Only two-thirds of respondents are fully functioning.

Those we surveyed reported inability to perform the following IADLs without assistance: meals (84\%), laundry $(70 \%)$, house cleaning (59\%), grocery shopping (67\%), managing money (34\%), taking medications (29\%), telephone (14\%), and transportation (43\%). Interestingly, among the most commonly reported of these problems, two are food-related: meal preparation and buying groceries. Consistent with findings regarding ADLs, prevalence of IADL limitations is lower among people living alone than among those living together with others. About one in five people living alone scored two or fewer on the Lawton Scale, while the prevalence among those living with others is twice as high $(P<.001)$.

\subsection{Unmet Social Service Needs}

In addition to food security, clients were asked about difficulty accessing other services including home care, Medicaid, SNAP assistance, transportation, medical care, protective services, and supportive counseling. They were also asked about unsafe living conditions. Thirteen percent of those interviewed have one or more unmet needs and 5\% have two or more unmet needs (of the eight items listed above). The prevalence of unmet needs varies significantly by race and ethnicity: eight percent of Whites have at least one unmet need, compared with $10 \%$ of Hispanics and $22 \%$ of Blacks $(P<.001)$.

Those clients who were not receiving home-delivered meals had nearly three times the prevalence of unmet needs as those who had meals delivered ( $31 \%$ vs. $11 \% ; P=.002)$. More than four in ten of those with one or more unmet needs were food insecure, compared with only $14 \%$ of those with no unmet needs $(P<.001)$. Rates of food security are higher among the oldest-old (aged 80 plus, $89 \%$ high food security) compared with younger respondents $(77 \% ; P=.001)$. We had originally hypothesized that since some home caregivers may help prepare meals, the existence of in-home paid caregivers might explain the difference in food security between older and younger seniors $(60 \%$ of older seniors but only $40 \%$ of younger ones have access to a paid caregiver; $P=.002$ ). However, we found no difference in food security between those with and without a paid caregiver.

\section{Policy Implications and Discussion}

Our finding that older citizens who receive home-delivered meals are more likely than those not receiving meals to be highly food secure may not be surprising, but a significant minority (13\%) of homebound seniors receiving home-delivered meals are still food insecure. Three factors were found to explain this: availability of meals from their ethnic background; not liking certain meal items; and, most importantly, receiving only one meal per day.

While food security is necessary, it alone is not sufficient for functional independence and good health. Even among those clients receiving home-delivered meals, over a third reported declining health, and more than $10 \%$ experienced unmet social service needs. Despite SNAP and other social safety net 
programs like Medicare, Medicaid, and Social Security, racial and ethnic differences in chronic health and unmet social-service needs exist among the older population, just as they do in the general population.

Our assessment provides a glimpse into the needs and food insecurity of homebound seniors in one community in New York City. Narratives from community organizers suggest that the elderly in the community are faring worse now than they had been only a few years earlier, before the 2007-2009 recession. This conclusion is supported by findings from the GAO that between 2007 and 2010 an estimated $79 \%$ of local senior agencies received increased requests for home-delivered meals, $73 \%$ experienced increased demand for support services, and 67\% report that more people are now seeking care-giving help (GAO, 2011). The general response from the national political establishment in the US, however, has amounted to further attempts to unravel the social safety net that now exists through proposed cuts to SNAP, Medicare and Social Security.

Predictors of food insecurity are likely to be predictors of other unmet social service needs and may adversely impact health and welfare among a country's most senior citizens. Our findings suggest that community-dwelling, homebound seniors have serious medical and health problems, multiple unmet social service needs, and often suffer from food insecurity. To a degree, these issues are interrelated and are affected by conservative political and economic policies. Even SNAP, which plays a critical role in our domestic hunger safety net for all families, has been under attack. Considering that only one-third of eligible elderly apply for these benefits (Cunnyngham, 2010), policymakers should be expanding outreach, administration, and funding of the program rather than imposing cuts that threaten to undermine it.

Understanding the relationship between food insecurity, unmet needs, and health problems is critical if community organizations and government agencies at all levels — even in wealthy countries - are to be more effective in assuring the well-being of their oldest residents. The Food and Agriculture Organizations of the United Nations (FAO, IFAD, \& WFP, 2014) have issued an urgent invitation for "sustained political commitment at the highest level" to eradicate hunger from the developing world. This is an invitation that policymakers in wealthy countries like the US should be more willing to accept when considering the plight of their own homebound seniors and other vulnerable populations.

\section{Acknowledgment}

Thanks to the Stella and Charles Guttman Foundation for their generous support of this work.

\section{References}

Andrews, M., \& Smallwood, D. (2012). What's behind the rise in SNAP participation? U.S. Department of Agriculture Economic Research Service. Retrieved February 22, 2014, from http://1.usa.gov/10ebZ1n

Bickel, G., Nord, M., Price, C., Hamilton, W., \& Cook, J. (2000). Measuring food security in the United 
States: Guide to measuring household food security. U.S. Department of Agriculture, Food and Nutrition Service.

Bolen, E., Rosenbaum, D., \& Dean, S. (2014). Summary of the 2014 Farm Bill Nutrition Title. Center on Budget and Policy Priorities. Retrieved February 3, 2015, from http://bit.ly/1uwnIVI

Coleman-Jensen, A., Nord, M., \& Singh, A. (2013). Household food security in the United States in 2012, ERR-155. U.S. Department of Agriculture, Economic Research Service. Retrieved February 16, 2015, from http://1.usa.gov/ 1y3p3EN

Cunnyngham, K. (2010). State trends in Supplemental Nutrition Assistance Program eligibility and participation among elderly individuals. Mathematica Policy Research, Inc. Retrieved February 20, 2015, from http://bit.ly/ 1tbE5Bu

FAO, IFAD, \& WFP. (2014). The state of food insecurity in the world 2014: Strengthening the enabling environment for food security and nutrition. Rome, FAO. Retrieved February 15, 2015, from http://www.fao.org/3/ a-i4030e.pdf

Food and Agriculture Organization of the United Nations (FAO). (2015). Retrieved February 15, 2015, from http://www.fao.org/home/en/

Greenstone, M., \& Looney, A. (2011). Building America's Job Skills with Effective Workforce Programs: A Training Strategy to Raise Wages and Increase Work Opportunities. Strategy Paper, the Hamilton Project. Retrieved September 29, 2014, from http://bit.ly/1tbCuLK

He, W., Sengupta, M., Velkoff, V. A., \& DeBarros, K. A. (2005). 65+ in the United States: 2005, U.S. Census Bureau, Current Population Reports (pp. 23-209). U.S. Government Printing Office, Washington, DC.

Hoefer, R., \& Curry, C. (2012). Food security and social protection in the United States. Journal of Policy Practice, 11, 59-76.

International Fund for Agricultural Development (IFAD). (2015). Retrieved February 15, 2015, from http://www.ifad.org/index.htm

Katz, S., Downs, T. D., Cash, H. R., \& Grotz, R. C. (1970). Progress in development of the index of ADL. Gerontologist, 10(Part 1), 20-30.

Lawton, M. P., \& Brody, E. M. (1969). Assessment of older people: Self-maintaining and instrumental activities of daily living. Gerontologist, 9(3), 179-186.

Nord, M. (2013). Food insecurity in U.S. households rarely persists over many years. U.S. Department of Agriculture, Economic Research Service. Retrieved September 29, 2013, from http://1.usa.gov/1u6fdPC

Rix, S. E. (2011). Recovering from the Great Recession: Long Struggle Ahead for Older Americans. AARP Public Policy Institute. Retrieved February 21, 2015, from http://bit.ly/Zkzy8J

Rosen, S., Meade, B., Fuglie, K., \& Rada, N. (2014). International Food Security Assessment, 2014-2024, GFA-25. U.S. Department of Agriculture, Economic Research Service. Retrieved February 15, 2015, from http://1.usa.gov/ 1u6e9v5 
Schiller, J. S., Lucas, J. W., Ward, B. W., \& Peregoy, J. A. (2012). Summary health statistics for U.S. adults: National Health Interview Survey, 2010. Vital Health Statistics, 10(252). Retrieved February 22, 2015, from http://1.usa.gov/1BwhB2B

Schwartz Center for Economic Policy Analysis. (2013). Retirement account balances by income: Even the highest earners don't have enough. Retrieved September 29, 2014, from http://bit.ly/1qOlOIv

Seligman, H. K., Bolger, A. F., Guzman, D., Guzman, A., \& Bibbins-Domingo, K. (2014). Exhaustion of food budgets at month's end and hospital admissions for hypoglycemia. Health Affairs, 33(1), 116-123.

U.S. Administration on Aging. (2013). Profile of Older Americans: 2013. Retrieved February 22, 2015, from http://bit.ly/1BD5WEd

U.S. Congress Joint Economic Committee Chairman's Staff. (2012). Retirement security after the great recession: Middle income and middle-aged Americans feeling the squeeze. Retrieved February 21, 2015, from http://1.usa.gov/YCoT8q

U.S. Department of Agriculture, Economic Research Service. (2013). Food security in the U.S.-history and background. Retrieved February 22, 2015, from http://1.usa.gov/10edhJI

U.S. Government Accountability Office. (2011). Older Americans Act: More should be done to measure the extent of unmet need for services. Retrieved February 22, 2015, from http://1.usa.gov/1CATv92

Van de Water, P. N., Sherman, A., \& Ruffing, K. A. (2013). Social Security keeps 22 million Americans out of poverty: A state-by-state analysis. Retrieved February 22, 2015, from http://bit.ly/1u6gExI

Ward, G., Jagger, C., \& Harper, W. (1998). A review of instrumental ADL assessments for use with elderly people. Reviews in Clinical Gerontology, 8(1), 65-71.

Weinfield, N. S., Mills, G., Borger, C., Gearing, M., Macaluso, T., Montaquila, J., \& Zedlewski, S. (2014). Hunger in America 2014: National Report Prepared for Feeding America. Retrieved February 21, 2015, from http://bit.ly/1pCsppc

World Food Programme (WFP). (2015). Retrieved February 15, 2015, from http://www.wfp.org/

Ziliak, J., \& Gundersen, C. (2011). Food insecurity among older Americans, prepared for the AARP Foundation. Retrieved February 15, 2015, from http://bit.ly/1AfuQX3

Ziliak, J., \& Gundersen, C. (2014). The health consequences of senior hunger in the United States: Evidence from the 1999-2010 NHANES. Retrieved February 15, 2015, from http://bit.ly/19p6P7f 